\title{
Assessment of Community Perception on Solid Waste Management Practice in Bedele Town, Oromia Region, Ethiopia
}

\author{
Ferede Abuye Fikiru Gamachu* Tefera Jegora \\ Mettu University, Bedelle College of Agriculture and Forestry, Department of Forestry, Bedele, Ethiopia
}

\begin{abstract}
Solid waste management is basic activities needs the participation of all individuals to increase the quality of environment and health. The aim of this study was to assess community perception on solid waste management practice in Bedelle Town, Oromia region, Ethiopia. Sampled households interview, field observation and key informants were used for data collection. Focus group discussion was also employed for the cross checks the data collected through interview. Food waste, plastic bags, plastic bottles, papers and cartons, cans and glass were some of solid waste released from each household and disposed to inappropriate disposal site and environment. Common diseases associated to poor solid waste management identified were common cold $(52.9 \%)$, respiratory track and shyness $(27 \%)$ and typhoid and cholera $(4.6 \%)$, respectively. Mean daily solid waste generation rate per capita per household in the town based on the current finding was $0.3240 \mathrm{~kg} / \mathrm{day} / \mathrm{house}$ hold. Also, the determinants willingness of urban community on solid waste management practice was also highlighted using linear regression model. Age, educational level, awareness and availability of training on solid waste for the urban community affect the attitude and willingness of urban communities to practice solid waste management. Generally the communities had very low thinking on the impact of improper solid waste management on the environmental condition. Therefore, the municipality should have to intervene with the integration of concerned stakeholders with appropriate waste management practices and disposal sites like landfill, demonstration sites.
\end{abstract}

Keywords: Solid waste, community perception, generation rate, solid waste management practice

DOI: $10.7176 / \mathrm{CER} / 11-10-01$

Publication date: November $30^{\text {th }} 2019$

\section{INTRODUCTION}

Solid wastes are non-liquid, non-soluble and non-decomposable or decomposable materials ranging from municipal garbage to industrial wastes that contain complex and sometimes hazardous substances. It is all inclusive, encompassing the heterogeneous mass of throw away from the urban community such as vegetables, food items, paper, plastics, rags, glass as well as more homogeneous accumulation of agricultural, industrial and mineral wastes (Mundhe et al., 2014). Solid waste is unwanted matter or material of any type (non-liquid), often that which is left after useful substances or parts have been removed (Williams, 2005). Both domestic and industrial waste generation continues to increase world-wide in tandem with growth in consumption (Okalebo et al., 2014) while quantity generated depends on the socioeconomic conditions, cultural habits of the people, urban structure, density of population, extent of commercial activity, and degree of salvaging at source (Ladu et al., 2011).

Solid waste management includes the entire process of dealing with solid waste, starting from the collection to ultimately disposing off it hygienically (Kumar and Pandit, 2013). Proper solid waste management reduces health risks to the public and lessens adverse environmental impacts, such as air, water and land pollution (Williams, 2005). Ladu et al., 2011 reported that a waste management system should not only ensure human health and safety, but it also environmentally and economically suitable. However, inappropriate methods of waste generation, handling, storage and disposal may pose serious risks to the environment and to public health (Asefa, 2017). Increasing population, booming economy, rapid urbanization and the rise in community living standards have greatly accelerated the municipal solid waste generation rate in developing countries (Minghua et al., 2009).

In the last few decades, there was a significant increase in solid waste generation in some cities of Ethiopia. This is largely because of rapid urbanization coupled with increased urban population and a rather economic development in the country (Mengist and Assegid, 2014; EPA, 2015). Bedele town is one among, where there is rapid growth of urban population as well as constraint in the management of solid wastes and its improper management gravely affects the public health and degrades environment. Thus, this study was carried out to investigate the perception of community towards solid waste and its management practices in Bedele town.

\section{Objectives of the Study \\ General Objective}

The overall objective of the study was to assess community perception on solid waste management practice in the study area

\section{Specific Objectives}

1. To identify the community perception towards solid waste management in the town 
2. To identify the common diseases caused by poor management of solid waste in the town

3. To evaluate rates of solid waste generation in the town

\section{Determinant Factors of Solid Waste Management in the Study Area Dependent variable}

The dependent variable for this study was solid waste management and community perception in the study area

\section{Independent variables}

On the other hand the following variables were hypothesized to affect solid waste management and community perception:

Age: - It is a continuous variable, which refers to the age of the household head measured in years.

Sex: - This is a dummy variable measured as 1 if the household head is female and 2, otherwise.

Education: - This variable will be measured in years of schooling and can be used as a proxy variable for managerial ability.

Family Size: - In this study, the number of persons the household head administers/supposed to manage will be considered as family members, regardless of blood relationship. This is continuous variable.

Income: - Refers to total annual income obtained from daily activities by the household head measured in birr.

Training: - It is a dummy variable representing access to training for solid waste management related activities. If the households have access to training, the variable takes a value of 1 and 2 , otherwise.

Perception: - It is a variable which measures communities' perception towards solid waste management

Job category: - It is a dummy variable representing job classes. The variable takes a value of 1 if farmers, 2 if traders, 3 if civil servant and 4, otherwise.

Dwellers' condition: - It is a dummy variable representing 1 if permanent dwellers and 2 if semi-urban

\section{MATERIALS AND METHODS \\ Study Area}

Bedele Woreda lies between $8^{\circ} 20^{\prime}-8035^{\prime} \mathrm{N}$ and $36^{\circ} 15^{\prime}-36^{\circ} 30^{\prime} \mathrm{E}$ at about $480 \mathrm{~km}$ road distance south-west of Addis Ababa. Administratively the woreda is located in Buno Bedele Zone at about 120km from Metu, Ilu Ababor zone capital. It is bounded by Borecha woreda in the east, Chora woreda in the west, Gachi woreda in the south and Dabo woreda in the north. It has 43 Kebeles, 41 rural and 2 towns. The total population in the woreda is 118,157 (male 58,510 and female 59,647). Agro-ecologically, the woreda is divided into three ecological zones namely mid-altitude (81.34\%), low-land (18.6\%) and highland (0.06\%). Altitude in the woreda ranges from 1300 to $2000 \mathrm{~m}$ a.s.l. The woreda is characterized as mixed farming system of coffee-crop-livestock production with a total area of 88,049 ha of land used for different purposes; annual crops (35801 ha), perennial crops (16549 ha), forest land (10047 ha), grazing land (10120 ha), wetland (1112 ha) and area not used for any purpose (14420 ha) (ADARDO, 2012).

\section{Data Source and Collection}

Kebele town was classified in to two administrative sub-cities using stratified sampling technique. A total of 8 household head for key informant interview, 16 household head for focus group discussion and 240 household head were randomly selected for structured, unstructured and semi-structured interview from each sub-city administrations. Data was collected from primary and secondary sources. The primary data was collected from sampled households' respondents, researchers' observation, focus group discussions and key informants. Closed and open-ended questionnaires were prepared to gather information on basic household economic and demographic characteristics, participation, acceptance, and awareness about solid waste management. Field observation was conducted throughout the whole process of the research in order to ensure the validity of information obtained from the urban dwellers. Two focus group discussions were held in each of the sub-city administration. The discussion was carried out with group of dwellers comprising 16 members that consists of Kebeles leaders, religious leaders, and targets dwellers with indigenous knowledge of waste management methods, teachers and development agents. Secondary data were collected from published materials such as reports, official records, census records, project reports, research papers and data files from web sites.

\section{Sampling Technique}

Bedele town was purposively selected based on the intensive solid waste generation as a result of rapidly over population through the flow of the community from different districts in the zone and from other zones and regions. Hence, waste disposal and management is a serious problem in the town due to population density, lack of awareness, absences of appropriate landfills and socio-economic condition. The study population was stratified into three groups based on job categories (namely farmer, trader, and civil servants). After stratification, simple random sampling was employed to select the representative households. The sample size was determined 
following the Yamane (1967) standard for sample size determination formula. A total of households living in the study were obtained from the city municipalities and sub-city administration. A total of 240 households (130 and 110 households from 01 and 02 kebele) was selected following the Yamane (1967) standard formula and calculated as:

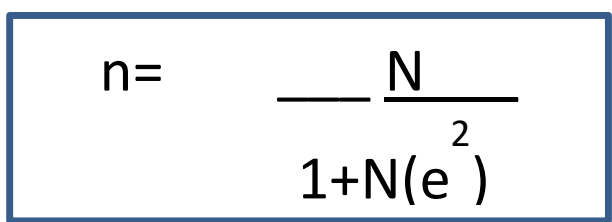

Where: $\mathrm{n}=$ desired sample size, $\mathrm{N}=$ the estimated population size and $\mathrm{e}=$ is level of precision $(0.05)$.

\section{Data Analysis}

The data collected from structured interview was systematically coded and analyzed using descriptive statistics by employing Statistical Package for Social Sciences (SPSS version 20) and presented using figure, pictures, tables and narration.

RESULTS AND DISCUSSION

Table 1: Back ground of the households by sex, age, education level, religion and occupation

\begin{tabular}{|c|c|c|c|}
\hline Back ground & Distinction & Frequency & Percent (\%) \\
\hline \multirow{3}{*}{ Sex } & Male & 159 & 66.3 \\
\hline & Female & 81 & 33.8 \\
\hline & Total & 240 & 100.0 \\
\hline \multirow{6}{*}{ Age } & $18-30$ & 56 & 23.3 \\
\hline & $31-40$ & 73 & 30.4 \\
\hline & $41-50$ & 54 & 22.5 \\
\hline & $51-60$ & 31 & 12.9 \\
\hline & $>60$ & 26 & 10.8 \\
\hline & Total & 240 & 100.0 \\
\hline \multirow{6}{*}{$\begin{array}{l}\text { Educational } \\
\text { status }\end{array}$} & Informal education & 29 & 12.1 \\
\hline & Elementary school & 51 & 21.3 \\
\hline & High school & 65 & 27.1 \\
\hline & Diploma holder & 42 & 17.5 \\
\hline & BSc and above & 53 & 22.1 \\
\hline & Total & 240 & 100.0 \\
\hline \multirow{6}{*}{ Religion } & Orthodox & 93 & 38.8 \\
\hline & Muslim & 61 & 25.4 \\
\hline & Protestant & 84 & 35.0 \\
\hline & Wakefata & 1 & 0.4 \\
\hline & Other & 1 & 0.4 \\
\hline & Total & 240 & 100.0 \\
\hline \multirow{6}{*}{ Occupation } & Trader & 45 & 18.8 \\
\hline & Government employer & 91 & 37.9 \\
\hline & Daily labor & 89 & 37.1 \\
\hline & NGO & 2 & 0.8 \\
\hline & Farmer & 13 & 5.4 \\
\hline & Total & 240 & 100.0 \\
\hline \multirow{5}{*}{$\begin{array}{l}\text { Business } \\
\text { activities }\end{array}$} & Hotel & 12 & 5.0 \\
\hline & Shop & 20 & 8.3 \\
\hline & Retailers & 13 & 5.4 \\
\hline & Others & 3 & 1.3 \\
\hline & Total & 48 & 20.0 \\
\hline
\end{tabular}

The percentage of male and female household heads respondents expressed as $66.3 \%$ and $33.8 \%$ respectively. The data recorded on the age category of the respondent shown that about $30.4 \%$ of the respondents had lie between $31-40$ age interval, while $23.3 \%$ and $22.5 \%$ were found at $18-30$ and $41-50$ age intervals respectively. A small number of respondents $(10.8 \%)$ had recorded in age above 60 years old. The table 1 also revealed that about $27.1 \%$, $22.1 \%, 21.3 \%, 17.5$ and $12.1 \%$ of respondents' educational level was high school, Bachelor degree, elementary school, diploma holder and basic education/informal education respectively. The religion of the respondents was Orthodox (38.8\%), Muslim (25.4\%), Protestant (35\%), and Wakefata (0.4\%) (Table1). 
The job category assessment of the respondents indicated that, trader (18.8\%), government employers (37.9\%), Daily laborers (37.1\%), NGO workers (0.8\%) and Farmers (5.4\%) (Table1). Out of 18.8\% traders 5.0\% of them were invested on hotel, whereas, $8.3 \%, 5.4 \%$ and $1.3 \%$ of them were invested on hotel, shop, retailers and others respectively. In the table below, majority of the surveyed households $62(26 \%)$ had 3 families, $19 \%$ had 4 families, and $16 \%$ and $15 \%$ had family sizes of 2 and 5 members per households respectively. However, less percentage $3 \%$ and $2 \%$ were recorded in family sizes of 7 and 8 families per households (Table, 2).

Table 2: Family size distribution of the study area respondents

\begin{tabular}{ccc}
\hline Number of Family size & Frequency & Percent $(\mathbf{\%})$ \\
\hline 1 & 24 & 10 \\
2 & 38 & 16 \\
3 & 62 & 26 \\
4 & 45 & 19 \\
5 & 35 & 15 \\
6 & 25 & 10 \\
7 & 7 & 3 \\
8 & 4 & 2 \\
\hline Total & $\mathbf{2 4 0}$ & $\mathbf{1 0 0}$
\end{tabular}

Waste generation rate in Bedele town

Table 3: Solid Waste Generation Rate in Bedele Town (one year data, 2018)

\begin{tabular}{ccc}
\hline Sub-Urban city/Kebele & $\begin{array}{c}\text { Waste Generated } \\
\text { (KG/Day/house hold) }\end{array}$ & $\begin{array}{c}\text { Waste Generated } \\
\text { (KG/Year/house hold) }\end{array}$ \\
\hline 01 Kebele & 0.351 & 128.203 \\
02 Kebele & 0.2965 & 108.297 \\
Total mean of solid waste generated per & 0.3240 & 236.50 \\
day/year & & \\
\hline
\end{tabular}

Urban waste generation increased in Bedele Town due to affluence and population development. In Bedele Town solid waste generation rate was found to be $0.2965 \mathrm{~kg} /$ household $/$ day, this is due to absence of awareness on solid waste management and minimization, lack of waste segregation /pit hall/ for individual solid waste damping. This was the data obtained only for the year of 2018 and it was increasing from year to year according the interview made with key informants during the survey in the town. In Bedele town the management of solid waste requires an immediate attention, because, countries such as Ethiopia, China, South Korea and Malysia, have been categorized as emerging industrialized countries as it is revealed by (Dawda et. al, 2012). As (Salim, 2008) reported in his finding, countries with low income have the lowest waste generation rates, similarly in this case it is averaging from $0.90 \mathrm{~kg}$ per capita per day to $0.05 \mathrm{~kg}$ per capita per day (Appendix table 1). From the total respondents this would be $71.17 \mathrm{~kg}$ /capita per day as it is highlighted on the appendix table 1 . So the annual solid waste generation for Bedele Town was $25994.8425 \mathrm{~kg} /$ year, whereas this was $108.311 \mathrm{~kg} /$ year/household.

\section{Community perception towards solid waste management}

For the effectiveness and efficient management of solid waste in a given area, the perception of local communities towards the solid waste management plays a crucial role. Here, as the information collected from the respondents, $211(87.9 \%)$ and $229(95.4 \%)$ of the respondents believed that mismanagement of the solid waste had a negative impact on the economy and health of the local communities in the study area respectively while about $12.1 \%$ and $4.6 \%$ of the respondents raised as solid waste had no any negative side on neighboring community economic and health status (Table, 4). 
Table 4: Local community's perception towards solid waste management

\begin{tabular}{llcc}
\hline Community perception & Response & Frequency & Percent \\
\hline & Yes & 211 & 87.9 \\
Do you think solid waste have economic impact? & No & 29 & 12.1 \\
\hline & Yes & 229 & 95.4 \\
Do you think solid waste have health impact? & No & 11 & 4.6 \\
\hline & Very high & 1 & 0.4 \\
& Medium & 15 & 6.3 \\
& Low & 86 & 35.8 \\
Do you think solid waste have an environmental impact? & Very low & 130 & 54.2 \\
& I don't know & 8 & 3.3 \\
\hline & Agree & 149 & 62.1 \\
Do you agree solid waste used as a resource? & Disagree & 46 & 19.1 \\
\hline
\end{tabular}

On the other hand, $149(62.1 \%)$ of the respondents agreed that solid waste used as a resources and about 46 (19.1\%) disagreed on the values of solid wastes. The rest $18.8 \%$ of the respondents didn't neither agree nor disagree on the use of solid wastes as a resource. Especially from the ecological role of proper solid waste management point of view, about $130(54.2 \%), 86(35.8 \%)$ and $15(6.3 \%)$ of the respondents had very low, low and medium degree of awareness respectively (Table, 4).

Table 5: Common disease resulted to poor management of solid waste in the study area

\begin{tabular}{|c|c|c|c|}
\hline & Disease types & Frequency & Percent \\
\hline \multirow{7}{*}{$\begin{array}{l}\text { What are common } \\
\text { diseases related to poor } \\
\text { solid waste? }\end{array}$} & Cholera & 2 & 0.8 \\
\hline & Common cold & 127 & 52.9 \\
\hline & Typhoid dysentery & 11 & 4.6 \\
\hline & Malaria & 5 & 2.1 \\
\hline & Cancer & 11 & 4.6 \\
\hline & Shyness (respiratory tracks and & 65 & 271 \\
\hline & Missing value & 19 & 7.9 \\
\hline & Total & 240 & 100.0 \\
\hline
\end{tabular}

Improper management of solid waste substance has its economical, ecological/environmental and health problems. Thus, the above table indicated the common diseases that affect human health due to improper management of human health. In the present finding, $52.9 \%$ of the respondents revealed that common cold ranked as the first disease and followed by shyness (respiratory tracks and asthma) which resulted from the improper solid waste management practices in the study area. The other waste related diseases rarely attack the health of human beings are typhoid dysentery, Cancer and Malaria. About $7.9 \%$ of the respondents did not responded on the types of diseases related to improper management of solid waste in the current study area (Table, 5).

\section{Binary outcome of logit model for urban community willingness on Solid waste management}

Age: Result shows that, age has significant and does affect the urban willingness on solid waste management practice in the areas as highlighted in the table below (Table 6). This show that, age has impact on the urban dwellers to bring difference to response solid waste management attitude in the area as indicated in the table below (Table 6). As age increased by one unit the urban community willingness on solid waste management increased by $0.97 \%$. The result agreed with (World Urbanization Prospects, 2005 ) which stated that age, were the key factors to determine urban communities' willingness to practice solid waste management in the town

Family size (F. Size): The result clearly showed that, family size was insignificant and has effect on urban communities' willingness to practice solid waste management by the dwellers in the area (Table 6). As family size increased by one unit the urban community willingness to practice solid waste management decreased by $3.02 \%$. From this table we can understood that, negative coefficient suggests that as family size increased, the willingness of urban community for solid waste management tends to decrease and the reverse is true according to this finding. This indicated that as the number of individuals in the family increases they consume more resources that contribute for the disposal of more solid wastes and became difficult to manage.

Educational level: Result shows that, educational level has significant and does affect the urban willingness on solid waste management practice in the areas as highlighted in the table below (Table 6). This showed that, educational level has impact on the urban dwellers to bring difference to respond on solid waste management attitude in the area as indicated in the table below (Table 6). As educational level increased by one unit the urban community willingness on solid waste management increased by $6.7 \%$. The previous finding on the ground also 
reported that, Educational level were the key factors determining urban communities' willingness to practice solid waste management (PEPAS, 1990). A positive coefficient indicates that as the value of the educational status increased, the mean of the willingness of urban community on solid waste management tends to increased. This indicated that educated persons understood more about the impacts of solid wastes on the human health and its environmental risks and pay more attention to keep their environment clean than the illiterate one.

Access to Waste information: The result shows that, access to waste information has significant and does affect the urban willingness on solid waste management practice in the areas as highlighted in the table below (Table 6). This show that, access to waste information has impact on the urban dwellers to bring difference to response solid waste management attitude in the area as indicated in the table below (Table 6). As access to waste information increased by one unit the urban community willingness on solid waste management increased by $16.915 \%$. A positive coefficient indicates that as the value of the access to waste information increased, the mean of the willingness of urban community on solid waste management tends to increased. Thus, well informed societies about the impacts of solid waste on the health of the environment are more active to manage the solid waste than the non-informed community.

Access to Training: Result shows that, access to training has significant and does affect the urban willingness on solid waste management practice in the areas as highlighted in the table below (Table 6). This show that, access to training has impact on the urban dwellers to bring difference to response solid waste management attitude in the area as indicated in the table below (Table 6). As access to training increased by one unit the urban community willingness on solid waste management increased by $29.045 \%$. The table indicates that as the value of access to training increased, the mean of the willingness of urban community on solid waste management tends to increased also.

Daily Laborers' Availability for Solid Waste collection: Result shows that, daily laborers' availability for solid waste collection has significant and affect the urban willingness on solid waste management practice in the areas as highlighted in the table below (Table 6). This shows that, daily laborers' availability has impact on the urban dwellers to bring difference to respond solid waste management attitude in the area as indicated in the table below (Table 6). As daily laborers' availability increased by one unit the urban community willingness on solid waste management increased by $3.56 \%$.

Table 6: Logit model on solid waste management

\begin{tabular}{lccccc}
\hline $\begin{array}{c}\text { Explanatory } \\
\text { Variable }\end{array}$ & Coeff. & Mfx. & Stand. Error & Prob. value & Constant \\
\hline Age & 0.0451544 & 0.0097 & 0.00412 & $0.019^{*}$ & 2.04090 \\
Fam.size & -0.14063381 & -0.0302 & 0.02881 & 0.294 & -1.76 \\
Edn.level & 0.0310787 & 0.067 & 0.02552 & $0.00794^{* *}$ & 0.078 \\
Waste info & 0.7877252 & 0.16915 & 0.9382 & $0.071^{*}$ & -7.60191 \\
Training & 1.352589 & 0.29045 & 0.17267 & $0.0093^{* *}$ & 0.3983 \\
Access of labor & 0.1656872 & 0.03558 & 0.06547 & $0.0587^{*}$ & 0.4312 \\
\hline
\end{tabular}

\section{CONCLUSION AND RECOMMENDATIONS}

\section{Conclusion}

Solid wastes were highly generated from every household from day-to-day in Bedele town. Lack of appropriate disposal site, lack of environmental awareness, low level of education and level of economical condition highly affect solid waste management in the study area. The community have been seen the problem of improper solid waste management on environment and human health. Thus, about $95 \%$ of the respondents raised mismanaged solid waste cause health problem while about $54 \%$ reported that the communities had very low thinking on the impact of improper solid waste management on the environmental condition.

\section{Recommendation}

Based on the above results, the following recommendation was given:

$\checkmark$ The local communities had informed on the problem of improper management of solid waste from different media sources. Therefore, the municipality should have trained the communities to aware them towards the effective and efficient solid waste management techniques.

$\checkmark$ The municipality should have to intervene with the integration of concerned stakeholders with appropriate waste management practices and disposal sites like landfill, demonstration sites etc.

$\checkmark \quad$ Further investigation must needed on socio-economic effects of improper solid waste disposals

\section{REFEENCES}

Asefa, A. W. (2017). Practicies of Solid Waste Management by Municipality and Community in Oromia Regional State of Ethiopia: a Case of Adama City, Ethiopia. SSRG International Journal of Agriculture \& Environmental Science (SSRG-IJAES)-volume 4 Issue 1 
CSA (Central Statistical Agency). 2007. Summary and Statistical Report of the 2007 Population and Housing Census Results. Addis Ababa

EPA. (2015). Oromia Regional State Environmental Protection Authority and Land Administration Bureau Report on REDD+ and CRGE Strategy, Finfinnee, Ethiopia.

Kumar, V and Pandit, R. K. (2013). Problems of Solid Waste Management in Indian Cities. International Journal of Scientific and Research Publications, Volume 3, Issue 3, ISSN 2250-3153

Ladu, J.L.C., X. Lu and M.A. Osman, 2011. Solid waste management and its Environmental impacts on human health in Juba town-South Sudan. Nat. Sci., 9: 27-35.

Mengist, H and Assegid, A. (2014). Solid Waste Management in Adama, Ethiopia: Aspects and Challenges. World Academy of Science, Engineering and Technology. International Journal of Environmental and Ecological Engineering. Vol:8, No:9

Minghua, Z., Xiumin, F., Rovetta, A., Qichang, H., Vicentini, F., Bingkai, L., Giusti, A. and Yi, L. (2009). Municipal solid waste management in Pudong New Area, China. J Waste Manage., 29, 1227-1233.

Mundhe, N., Ravindra Jaybhaye, R and Dorik, B. (2014). Assessment of Municipal Solid Waste Management of Pune City using Geospatial Tools. Pune, India. International Journal of Computer Applications. Volume 100 No.10, pp 0975 - 8887

Okalebo, S.E., Opata, G.P and Mwasi, B. N. (2014). An analysis of the household solid waste generation patterns and prevailing management practices in Eldoret town, Kenya. Int. J. Agric. Pol. Res. 2(2):pp. 076-089.

Williams, P. T. (2005). Waste Treatment and Disposal. John Wiley and Sons, USA.

World Bank. (2005). "Waste Management in China: Issues and Recommendations," East Asia. Infrastructure Development, http://www.sciencedirect.com/science/

Yamane, T. (1967). Statistics; An Introductory Analysis: New York, Harper and Row publishers. 